\section{Has the gout epidemic peaked in the UK? A nationwide cohort study using data from the Clinical Practice Research Datalink, from 1997 to across the COVID-19 pandemic in 2021}

The burden of gout increased globally across the 20th and 21st centuries. ${ }^{1}$ However, a study using cross-sectional datasets demonstrated stable prevalence of hyperuricaemia and gout in the USA between 2007 and 2016. ${ }^{2}$ Additionally, given poor persistence with urate-lowering treatment (ULT), the impact of COVID-19 pandemic on ULT prescription in a nationwide cohort merits assessment to ascertain any detrimental impact. ${ }^{3}$ The objectives of this study were to examine temporal trends in incidence and prevalence of gout, and ULT prescription between 1997 and 2021.

Anonymised data from Clinical Practice Research Datalink (CPRD), one of the largest databases of electronic health records originating during routine clinical care, were used. The study spanned from 01 January 1997 to 31 August 2021. Gout status and ULT prescriptions were ascertained using Read and product codes (online supplemental material).

Point prevalence (95\% CIs) of gout on 1 July of each year was calculated with CPRD population registered on that date as denominator. Incidence $(95 \% \mathrm{CI})$ of gout per 1000 person-years in each calendar year was calculated using number of incident cases and total follow-up period in that year. The incidence and prevalence were directly standardised to the study population for age, sex and length of registration in $\mathrm{CPRD}^{3}$ (online supplemental material). Proportion $(95 \% \mathrm{CI})$ of prevalent gout cases prescribed ULT within 90 days prior to 1 July in each year, and incident gout cases prescribed ULT within 1 year of diagnosis were calculated and directly standardised to the relevant study populations. Standardised rates were used to examine temporal trend using joinpoints analysis. Crude rates for 1999 and 2021 were stratified by age and sex to compare age-sex distribution of gout before and during the COVID-19 pandemic.

Data for 373371 patients with gout were included. The standardised prevalence $(95 \% \mathrm{CI})$ of gout increased from $0.98 \%$ $(0.97 \%$ to $0.96 \%)$ in 1997 to $2.33 \%$ (2.31\% to $2.35 \%)$ in 2021 , with annual average percentage change (AAPC) (95\% CI) 3.9\% (3.3\% to $4.4 \%)$ (figure 1$)$. The standardised incidence $(95 \% \mathrm{CI})$ of gout increased from 1.31 (1.26 to 1.37$) / 1000$ person-years in 1997 to 1.97 (1.94 to 2.01$) / 1000$ person-years in 2013, and reduced to 0.98 (0.94 to 1.03$) / 1000$ person-years in 2021 . The standardised prevalence of ULT prescription increased from $25.92 \%$ in 1997 to $39.53 \%$ in 2021 (AAPC (95\% CI) $1.3 \%$ $(1.0 \%$ to $1.5 \%)$ ), whereas the proportion of incident gout cases prescribed ULT within 1 year reduced. Fewer women than men were prescribed ULT ever, and within 1 year of diagnosis, despite older age at onset and higher comorbidity burden as reported previously. ${ }^{4}$

The standardised prevalence of gout remained stable across the pandemic while the standardised incidence $(95 \% \mathrm{CI})$ reduced from 1.54 (1.50 to 1.58$) / 1000$ person-years in 2019 , to 1.07 (1.00 to 1.07 ) and 0.98 (0.94 to 1.03$) / 1000$ person-years in 2020 and 2021, respectively. The age-sex distribution of prevalent gout was similar in 2019 and 2021 (online supplemental figure S1). However, gout incidence was significantly lower in 2021 than in 2019 across all ages and in both sexes (online supplemental figure S1). The prevalence $(95 \% \mathrm{CI})$ of ULT prescription in gout improved from $36.72 \%(36.41 \%$ to $37.02 \%)$ in 2019 to $39.53 \%$ (39.19\% to $39.91 \%)$ in 2021 .

The gout epidemic appears to have peaked in the UK in 2013, with a significant reduction in incidence between 2013 and 2019, that is, before the COVID-19 pandemic potentially due to reduction in alcohol and red meat consumption. ${ }^{56}$ The sharp
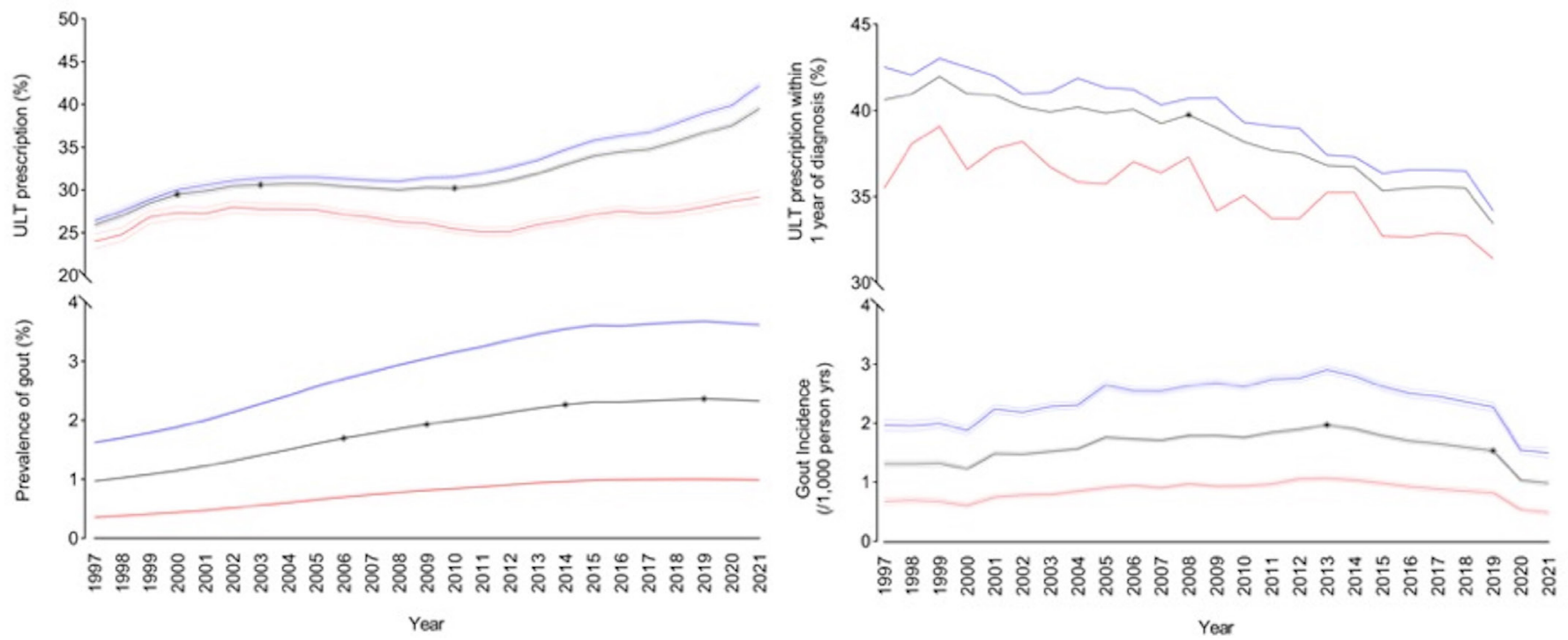

Figure 1 Temporal trend 1997-2021. Gout prevalence (lower left panel). The APCs (95\% Cl) were 6.6\% (6.4\% to 6.8\%), 4.4\% (2.7\% to 6.0\%), 3.3\% (2.8\% to $3.8 \%), 0.8 \%(0.2 \%$ to $1.3 \%)$, and $-0.8 \%(-2.9 \%$ to $1.3 \%)$ in 1997-2006, 2006-2009, 2009-2014, 2014-2019, 2019-2021, respectively. Gout incidence (lower right panel). The APCs (95\% Cl) during 1997-2013, 2013-2019, and 2019-2021 were 2.6\% (2.0\% to 3.2\%), -4.5\% (-7.2\% to $-1.8 \%)$, and $-23.2 \%(-39.0 \%$ to $-3.3 \%)$, respectively. ULT prevalence (upper left panel). The APCs (95\% CI) between 1997 and 2000,2000 and 2003,2003 and 2010,2010 and 2021 were $4.5 \%$ (2.4\% to $6.6 \%), 1.4 \%(-1.9 \%$ to $4.8 \%),-0.4 \%(-0.9 \%$ to $0.1 \%)$ and $2.3 \%(2.1 \%$ to $2.5 \%)$, respectively. ULT prescription within 1 year of diagnosis (upper right panel). The APCs (95\% CI) between 1997 and 2008,2008 and 2019 were $-0.4 \%$ $(-0.7 \%$ to $-0.2 \%)$ and $-1.3 \%(-1.5 \%$ to $-1.1 \%)$, respectively. The APC $(95 \% \mathrm{Cl})$ reported are for the overall gout population. * Significant joinpoints. Blue line male, red line female, black line overall. Dotted lines $95 \% \mathrm{CI}$. APC, average percentage change; ULT, urate-lowering treatment. 
decline in its incidence during the COVID-19 pandemic likely represents underdiagnosis, potentially because of the inability to seek healthcare due to restrictions imposed on the population and COVID-19-related workload on the health service, rather than due to improved lifestyle, as alcohol consumption increased during COVID-19 pandemic. $^{7}$ However, this may cause a surge in gout cases presenting to health services in the near future.

Overall, ULT prescriptions increased steadily since 2010, without any detrimental impact of the COVID-19 pandemic, as observed for other rheumatic diseases. ${ }^{8}$ While encouraging, additional steps, for example, partnership with primary care and guideline implementation are needed for continued improvement. The modest increase in ULT among prevalent gout cases during the pandemic may be driven by worsening gout control, potentially due to increased alcohol consumption, ${ }^{7}$ as prevalence of first ULT prescription within 1 year of diagnosis continued to decline in this period.

\section{Abhishek Abhishek $\odot,{ }^{1}$ Laila J Tata, ${ }^{2}$ Mamas Mamas, ${ }^{3}$ Anthony J Avery ${ }^{4}$ \\ ${ }^{1}$ Academic Rheumatology, University of Nottingham, Nottingham, UK \\ ${ }^{2}$ Population Sciences, University of Nottingham, Nottingham, UK \\ ${ }^{3}$ Keele Cardiovascular Research Group, Keele University, Stoke on Trent, UK \\ ${ }^{4}$ Population and Lifespan Sciences, University of Nottingham, Nottingham, UK}

Correspondence to Dr Abhishek Abhishek, University of Nottingham, Nottingham NG7 2RD, UK; abhishek.abhishek@nottingham.ac.uk

\section{Handling editor Josef S Smolen}

Contributors AA conceived the idea for the study, contributed to the study design, performed the analysis, interpreted the results and critically reviewed the paper. AJA contributed to the study design and interpretation of the results, and critically reviewed the paper. LJT contributed to the study design, advised on the analysis and interpretation of the results, and critically reviewed the paper. MM contributed to the study design and critically reviewed the paper.

Funding The authors have not declared a specific grant for this research from any funding agency in the public, commercial or not-for-profit sectors.

Competing interests AA has received departmental research grants from AstraZeneca and Oxford Immunotec, speaker bureau fees from Menarini, scientific meeting support from Pfizer, consulting fees from Inflazome, speaker fees from Cadilla pharmaceuticals, and author royalties from UpToDate and Springer, unrelated to this work.

Patient consent for publication Not required.

Ethics approval This study involves human participants and was approved by the Independent Scientific Advisory Committee (ISAC) of the Medicines and Healthcare Regulatory Authority (MHRA) (Ref: 20_000233). Participants consent to the GPS giving anonymous data to CPRD for research purposes. CPRD then make this data available to researchers for research projects approved by the ISAC.
Provenance and peer review Not commissioned; externally peer reviewed.

Supplemental material This content has been supplied by the author(s). It has not been vetted by BMJ Publishing Group Limited (BMJ) and may not have been peer-reviewed. Any opinions or recommendations discussed are solely those of the author(s) and are not endorsed by BMJ. BMJ disclaims all liability and responsibility arising from any reliance placed on the content. Where the content includes any translated material, BMJ does not warrant the accuracy and reliability of the translations (including but not limited to local regulations, clinical guidelines, terminology, drug names and drug dosages), and is not responsible for any error and/or omissions arising from translation and adaptation or otherwise.

(c) Author(s) (or their employer(s)) 2022. No commercial re-use. See rights and permissions. Published by BMJ.

- Additional supplemental material is published online only. To view, please visit the journal online (http://dx.doi.org/10.1136/annrheumdis-2021-221989).

\section{Check for updates}

To cite Abhishek A, Tata LJ, Mamas M, et al. Ann Rheum Dis Epub ahead of print: [please include Day Month Year]. doi:10.1136/annrheumdis-2021-221989

Received 11 December 2021

Accepted 15 January 2022

Ann Rheum Dis 2022;0:1-2. doi:10.1136/annrheumdis-2021-221989

ORCID iD

Abhishek Abhishek http://orcid.org/0000-0003-0121-4919

\section{REFERENCES}

1 Singh JA, Gaffo A. Gout epidemiology and comorbidities. Semin Arthritis Rheum 2020;50:S11-16.

2 Chen-Xu M, Yokose C, Rai SK, et al. Contemporary prevalence of gout and hyperuricemia in the United States and Decadal trends: the National health and nutrition examination survey, 2007-2016. Arthritis Rheumatol 2019;71:991-9.

3 Kuo C-F, Grainge MJ, Mallen C, et al. Rising burden of gout in the UK but continuing suboptimal management: a nationwide population study. Ann Rheum Dis 2015;74:661-7.

4 Drivelegka P, Sigurdardottir V, Svärd A, et al. Comorbidity in gout at the time of first diagnosis: sex differences that may have implications for dosing of urate lowering therapy. Arthritis Res Ther 2018;20:108.

5 Adults health related behaviours. Health survey for England 2019. published 2020. NHS digital. Available: https://files.digital.nhs.uk/D4/93337C/HSE19-Adult-healthbehaviours-rep.pdf [Accessed 31 Oct 2021].

6 Stewart C, Piernas C, Cook B, et al. Trends in UK meat consumption: analysis of data from years 1-11 (2008-09 to 2018-19) of the National diet and nutrition survey rolling programme. Lancet Planet Health 2021;5:e699-708.

7 Niedzwiedz CL, Green MJ, Benzeval M, et al. Mental health and health behaviours before and during the initial phase of the COVID-19 lockdown: longitudinal analyses of the UK household longitudinal study. J Epidemiol Community Health 2021;75:224-31.

8 Hausmann JS, Kennedy K, Simard JF, et al. Immediate effect of the COVID-19 pandemic on patient health, health-care use, and behaviours: results from an international survey of people with rheumatic diseases. Lancet Rheumatol 2021;3:e707-14. 